International Journal of Applied Mathematics

Volume 32 No. $6 \quad 2019,1051-1067$

ISSN: 1311-1728 (printed version); ISSN: 1314-8060 (on-line version)

doi: http://dx.doi.org/10.12732/ijam.v32i6.11

\title{
TOPOLOGICAL CHARACTERIZATION FOR THE LINE GRAPH OF NANOSTRUCTURES
}

\author{
Jianzhong $\mathrm{Xu}^{1}$, Muhammad K. Siddiqui ${ }^{\S}$, \\ Muhammad Imran ${ }^{3,4}$ \\ ${ }^{1}$ Department of Electronics and Information Engineering \\ Bozhou University, Bozhou 236800, CHINA \\ 2 Department of Mathematics \\ COMSATS University Islamabad \\ Lahore Campus, 54000 - PAKISTAN \\ ${ }^{3}$ Department of Mathematical Sciences \\ United Arab Emirates University, P.O. Box 15551 \\ Al Ain, UNITED ARAB EMIRATES \\ ${ }^{4}$ Department of Mathematics \\ School of Natural Sciences (SNS) \\ National University of Sciences and Technology (NUST) \\ Sector H-12, Islamabad, PAKISTAN
}

\begin{abstract}
A numerical quantity that characterizes the whole structure of a graph is called a topological index. More preciously topological indices are numbers associated with molecular graphs for the purpose of allowing quantitative structure-activity/ property/ toxicity relationships. These topological indices correlate certain physico-chemical properties like boiling point, stability, strain energy etc of chemical compounds. The concepts of hyper Zagreb index, first multiple Zagreb index, second multiple Zagreb index and Zagreb polynomials were established in chemical graph theory based on vertex degrees. These indices are useful in the study of anti-inflammatory activities of certain chemical networks. In this paper, we determine the hyper Zagreb index, first multiple Zagreb index, second multiple Zagreb index and Zagreb polynomials of the line graph of $2 D$-lattice, nanotube and nanotorus of $T U C_{4} C_{8}[p, q]$ by using the concept of subdivision.
\end{abstract}

Received: June 17, 2019

(c) 2019 Academic Publications

$\S$ Correspondence author 
AMS Subject Classification: $05 \mathrm{C} 12,37 \mathrm{~B} 30$

Key Words: hyper Zagreb index, multiple Zagreb index, Zagreb polynomials, line graph, subdivision graph, nanostructures

\section{Introduction}

Chemical graph theory is a branch of mathematical chemistry in which we apply tools of graph theory to model the chemical phenomenon mathematically. This theory contributes a prominent role in the fields of chemical sciences. A moleculer/ chemical graph is a simple finite graph in which vertices denote the atoms and edges denote the chemical bonds in underlying chemical structure. This is more important to say that the hydrogen atoms are often omitted in any molecular graph. A topological index is actually a numeric quantity associated with chemical constitution purporting for correlation of chemical structure with many physio-chemical properties, chemical reactivity or you can say that biological activity. Topological descriptors play a vital role in Quantitative structure-activity (QSAR) and structure- property (QSPR) study.

A nano structure is an object of intermediate size between microscopic and molecular structures. It is product derived through engineering at molecular scale. This is the something that has a physical dimension smaller than 100 nanometers, ranging from clusters of atoms to dimensional layers. Carbon nanotubes (CNTs) are types of nanostructure which are allotropes of carbon and having a cylindrical shape.

In last decade, graph theory has found a considerable use in this area of research. Graph theory has provided chemist with a variety of useful tools, such as topological indices. Cheminformatics is new subject which is a combination of chemistry, mathematics and information science. It studies Quantitative structure-activity (QSAR) and structure-property (QSPR) relationships that are used to predict the biological activities and properties of chemical compounds. In the QSAR / QSPR study, physico-chemical properties and topological indices such as Hyper-Zagreb index, first multiple Zagreb index, second multiple Zagreb index and Zagreb polynomials are used to predict bioactivity of the chemical compounds.

Molecules and molecular compounds are often modeled by molecular graph. A molecular graph is a representation of the structural formula of a chemical compound in terms of graph theory, whose vertices correspond to the atoms of the compound and edges correspond to chemical bonds. A graph $G(V, E)$ with vertex set $V$ and edge set $E$ is connected, if there exists a connection between 
any pair of vertices in $G$. A network is simply a connected graph having no multiple edges and no loops. For a graph $G$, the degree of a vertex $v$ is the number of edges incident to $v$ and denoted by $\operatorname{deg}(v)$.

A graph can be recognized by a numeric number, a polynomial, a sequence of numbers or a matrix which represents the whole graph, and these representations are aimed to be uniquely defined for that graph. A topological index is a numeric quantity associated with a graph which characterize the topology of graph and is invariant under graph automorphism. There are some major classes of topological indices such as distance based topological indices, degree based topological indices and counting related polynomials and indices of graphs. Among these classes degree based topological indices are of great importance and play a vital role in chemical graph theory and particularly in chemistry. In more precise way, a topological index $\operatorname{Top}(G)$ of a graph $G$, is a number with the property that for every graph $H$ isomorphic to $G$, $\operatorname{Top}(H)=\operatorname{Top}(G)$. The concept of topological index came from work done by Wiener [30] while he was working on boiling point of paraffin. He named this index as path number. Later on, the path number was renamed as Wiener index. The Wiener index is the first and most studied topological index, both from theoretical point of view and applications, and defined as the sum of distances between all pairs of vertices in $G$, see for details [13].

One of the oldest topological index is the first Zagreb index an introduced by Gutman and Trinajstic on based degree of vertices of $G$ in 1972, [14]. The first and second Zagreb indices of a graph $G$ are defined as:

$$
\begin{aligned}
& M_{1}(G)=\sum_{u v \in E(G)}[\operatorname{deg}(u)+\operatorname{deg}(v)], \\
& M_{2}(G)=\sum_{u v \in E(G)}[\operatorname{deg}(u) \times \operatorname{deg}(v)] .
\end{aligned}
$$

In 2013, Shirdel, RezaPour and Sayadi [28] introduced a new degree based of Zagreb index named "hyper Zagreb index" as:

$$
H M(G)=\sum_{u v \in E(G)}[\operatorname{deg}(u)+\operatorname{deg}(v)]^{2} .
$$

Ghorbani and Azimi defined two new versions of Zagreb indices of a graph $G$ in 2012, [10]. The first multiple Zagreb index $P M_{1}(G)$, second multiple Zagreb index $P M_{2}(G)$ and these indices are defined as:

$$
P M_{1}(G)=\prod_{u v \in E(G)}[\operatorname{deg}(u)+\operatorname{deg}(v)],
$$




$$
P M_{2}(G)=\prod_{u v \in E(G)}[\operatorname{deg}(u) \times \operatorname{deg}(v)] .
$$

The properties of $P M_{1}(G), P M_{2}(G)$ indices for some chemical structures have been studied in $[4,10]$.

The first Zagreb polynomial $M_{1}(G, x)$ and second Zagreb polynomial $M_{2}(G, x)$ are defined as:

$$
\begin{aligned}
& M_{1}(G, x)=\sum_{u v \in E(G)} x^{[\operatorname{deg}(u)+\operatorname{deg}(v)]}, \\
& M_{2}(G, x)=\sum_{u v \in E(G)} x^{[\operatorname{deg}(u) \times \operatorname{deg}(v)]} .
\end{aligned}
$$

The properties of $M_{1}(G, x), M_{2}(G, x)$ polynomials for some chemical structures have been studied in [12].

Nowadays there is an extensive research activity on the $H M(G), P M_{1}(G)$, $P M_{2}(G)$ indices and $M_{1}(G, x), M_{1}(G, x)$, polynomials and their variants, see also $[4,5,7,8,9,10,14,15,28]$. For further study of topological indices of various graph families, see $[1,2,3,6,15,16,17,21,22,25,26,27]$.

\section{Topological indices of $L(S(G))$}

The subdivision graph $[23,24] S(G)$ is the graph obtained from $G$ by replacing each of its edge by a path of length 2 , or equivalently, by inserting an additional vertex into each edge of $G$, [4]. The line graph of the graph $G$, written $L(G)$, is the simple graph whose vertices are the edges of $G$, with ef $\in E(L(G))$ when $e$ and $f$ have a common end point in $G$. In 2011, Ranjini et al. calculated the explicit expressions for the Shultz indices of the subdivision graphs of the tadpole, wheel, helm and ladder graphs, [24]. They also studied the Zagreb indices of the line graphs of the tadpole, wheel and ladder graphs with subdivision in [23]. In 2015, Su and Xu calculate the general sum-connectivity indices and co-indices of the line graphs of the tadpole, wheel and ladder graphs with subdivision in [29]. In [19, 20], Nadeem et al. computed $A B C_{4}$ and $G A_{5}$ indices of the line graphs of the tadpole, wheel, ladder, $2 D$-lattice, nanotube and nanotorus of $T U C_{4} C_{8}[p, q]$ graphs by using the notion of subdivision.

In this paper, we compute hyper Zagreb index, first multiple Zagreb index, second multiple Zagreb index, Zagreb polynomials for the line graph of subdivision graphs of $2 D$-lattice, nanotube and nanotorus of $T U C_{4} C_{8}[p, q]$. Let $p$ and $q$ denote the number of squares in a row and the number of rows of squares, 


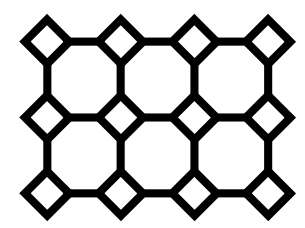

(a)

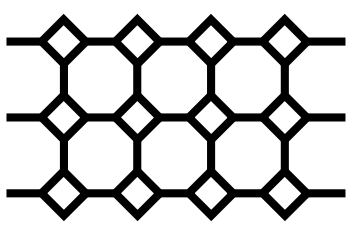

(b)

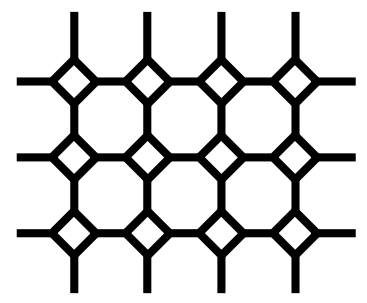

(c)

Figure 1: (a) $2 D$-lattice of $T U C_{4} C_{8}[4,3]$; (b) $T U C_{4} C_{8}[4,3]$ nanotube; (c) $T U C_{4} C_{8}[4,3]$ nanotorus.

respectively in $2 D$-lattice, nanotube and nanotorus of $T U C_{4} C_{8}[p, q]$ as shown in Fig. 1 (a), (b), and (c), respectively.

The numbers of vertices and edges of $2 D$-lattice, nanotube and nanotorus of $T U C_{4} C_{8}[p, q]$ are given in Table 1.

\begin{tabular}{|c|c|c|}
\hline Graph & No of vertices & No of edges \\
\hline $2 D-$ lattice of $T U C_{4} C_{8}[p, q]$ & $4 p q$ & $6 p q-p-q$ \\
\hline$T U C_{4} C_{8}[p, q]$ nanotube & $4 p q$ & $6 p q-p$ \\
\hline$T U C_{4} C_{8}[p, q]$ nanotorus & $4 p q$ & $6 p q$ \\
\hline
\end{tabular}

Table 1: Numbers of vertices and edges.

Lemma 1. Let $G$ be a graph. Then $\sum_{u \in V(G)} d_{u}=2|E(G)|$.

This is also known as handshaking lemma.

2.1. Zagreb indices and Zagreb polynomials of line graph of the subdivision graph of $2 \mathrm{D}$ lattice of $T U C_{4} C_{8}[p, q]$

Theorem 2. Let $R$ be the line graph of the subdivision graph of $2 D$-lattice of $T U C_{4} C_{8}[p, q]$. Then

$$
\begin{aligned}
M_{1}(R) & =108 p q-38(p+q), \\
M_{2}(R) & =162 p q-67(p+q)+4, \\
H M(R) & =648 p q-264(p+q)+8, \\
P M_{1}(R) & =4^{(2 p+2 q+4)} \times 5^{(4 p+4 q-8)} \times 6^{(18 p q-11 p-11 q+4),}
\end{aligned}
$$




$$
\begin{aligned}
P M_{2}(R) & =4^{(2 p+2 q+4)} \times 6^{(4 p+4 q-8)} \times 9^{(18 p q-11 p-11 q+4)}, \\
M_{1}(R, x) & =\left((2 p+2 q+4) x^{4}+(4 p+4 q-8) x^{5}\right. \\
& +(18 p q-11 p-11 q+4) x^{6} \\
M_{2}(R, x) & =(2 p+2 q+4) x^{4}+(4 p+4 q-8) x^{6} \\
& +(18 p q-11 p-11 q+4) x^{9} .
\end{aligned}
$$

Proof. The subdivision graph of $2 D$-lattice of $T U C_{4} C_{8}[p, q]$ and the graph $R$ are shown in Fig. 2 (a) and (b) respectively. In $R$ there are total $2(6 p q-p-q)$ vertices among which $4(p+q)$ vertices are of degree 2 and remaining all the vertices of degree 3 . It is easy to see from Lemma 1 that the total number of edges of $R$ is $18 p q-5 p-5 q$. The edge set $E(R)$ divides into three edge partitions based on degrees of vend vertices,

$$
\begin{aligned}
& E_{1}(R)=\{u v \in E(R) \mid \operatorname{deg}(u)=2, \operatorname{deg}(v)=2\}, \\
& E_{2}(R)=\{u v \in E(R) \mid \operatorname{deg}(u)=2, \operatorname{deg}(v)=3\}, \\
& E_{3}(R)=\{u v \in E(R) \mid \operatorname{deg}(u)=3, \operatorname{deg}(v)=3\} .
\end{aligned}
$$

Among these three partitions of edge set correspond to their degree sum of neighbors of end vertices the number of edges in $E_{1}(R)$ are $2 p+2 q+4$, in $E_{2}(R)$ are $4 p+4 q-8$ and in $E_{3}(R)$ are $18 p q-11 p-11 q+4$. Now using equations $[(1)-(7)]$, we have

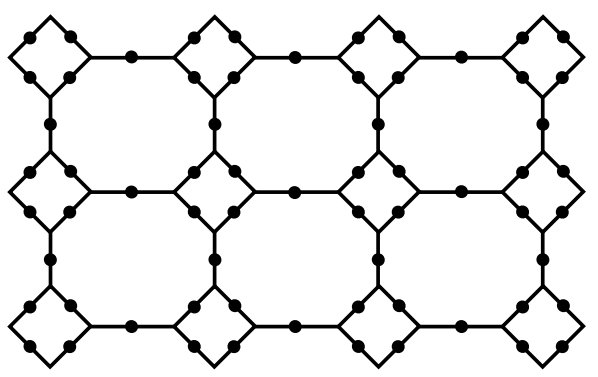

(a)

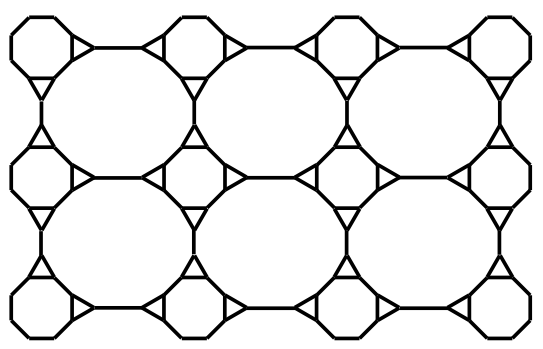

(b)

Figure 2: (a) Subdivision of $2 D$-lattice of $T U C_{4} C_{8}[4,3]$; (b) Line graph of the subdivision graph of $2 D$-lattice of $T U C_{4} C_{8}[4,3]$.

$$
M_{1}(G)=\sum_{u v \in E(G)}[\operatorname{deg}(u)+\operatorname{deg}(v)]
$$




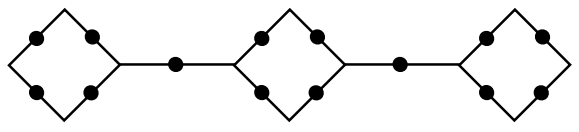

(a)

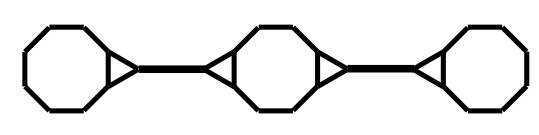

(b)

Figure 3: (a) Subdivision of $2 D$-lattice of $T U C_{4} C_{8}[3,1]$; (b) Line graph of the subdivision graph of $2 D$-lattice of $T U C_{4} C_{8}[3,1]$.

$$
\begin{aligned}
& M_{1}(R)=\sum_{u v \in E_{1}(R)}[\operatorname{deg}(u)+\operatorname{deg}(v)] \\
& +\sum_{u v \in E_{2}(R)}[\operatorname{deg}(u)+\operatorname{deg}(v)]+\sum_{u v \in E_{3}(R)}[\operatorname{deg}(u)+\operatorname{deg}(v)], \\
& =4\left|E_{1}(R)\right|+5\left|E_{2}(R)\right|+6\left|E_{3}(R)\right|, \\
& =4(2 p+2 q+4)+5(4 p+4 q-8) \\
& +6(18 p q-11 p-11 q+4)=108 p q-38(p+q), \\
& M_{2}(G)=\sum_{u v \in E(G)}[\operatorname{deg}(u) \times \operatorname{deg}(v)] \text {, } \\
& M_{2}(R)=\sum_{u v \in E_{1}(R)}[\operatorname{deg}(u) \times \operatorname{deg}(v)] \\
& +\sum_{u v \in E_{2}(R)}[\operatorname{deg}(u) \times \operatorname{deg}(v)]+\sum_{u v \in E_{3}(R)}[\operatorname{deg}(u) \times \operatorname{deg}(v)], \\
& =4\left|E_{1}(R)\right|+6\left|E_{2}(R)\right|+9\left|E_{3}(R)\right|, \\
& =4(2 p+2 q+4)+6(4 p+4 q-8) \\
& +9(18 p q-11 p-11 q+4)=162 p q-67(p+q)+4, \\
& H M(G)=\sum_{u v \in E(G)}[\operatorname{deg}(u)+\operatorname{deg}(v)]^{2}, \\
& H M(R)=\sum_{u v \in E_{1}(R)}[\operatorname{deg}(u)+\operatorname{deg}(v)]^{2} \\
& +\sum_{u v \in E_{2}(R)}[\operatorname{deg}(u)+\operatorname{deg}(v)]^{2}+\sum_{u v \in E_{3}(R)}[\operatorname{deg}(u)+\operatorname{deg}(v)]^{2}, \\
& =16\left|E_{1}(R)\right|+25\left|E_{2}(R)\right|+36\left|E_{3}(R)\right| \text {, } \\
& =16(2 p+2 q+4)+25(4 p+4 q-8)
\end{aligned}
$$




$$
\begin{aligned}
& +36(18 p q-11 p-11 q+4)=648 p q-264(p+q)+8 \\
& P M_{1}(G)=\prod_{u v \in E(G)}[\operatorname{deg}(u)+\operatorname{deg}(v)], \\
& P M_{1}(R)=\prod_{u v \in E_{1}(R)}[\operatorname{deg}(u)+\operatorname{deg}(v)] \\
& \times \prod_{u v \in E_{2}(R)}[\operatorname{deg}(u)+\operatorname{deg}(v)] \times \prod_{u v \in E_{3}(R)}[\operatorname{deg}(u)+\operatorname{deg}(v)], \\
& =4^{\left|E_{1}(R)\right|} \times 5^{\left|E_{2}(R)\right|} \times 6^{\left|E_{3}(R)\right|}, \\
& =4^{(2 p+2 q+4)} \times 5^{(4 p+4 q-8)} \times 6^{(18 p q-11 p-11 q+4)}, \\
& P M_{2}(G)=\prod_{u v \in E(G)}[\operatorname{deg}(u) \times \operatorname{deg}(v)] \\
& P M_{2}(R)=\prod_{u v \in E_{1}(R)}[\operatorname{deg}(u) \times \operatorname{deg}(v)] \\
& \times \prod_{u v \in E_{2}(R)}[\operatorname{deg}(u) \times \operatorname{deg}(v)] \times \prod_{u v \in E_{3}(R)}[\operatorname{deg}(u) \times \operatorname{deg}(v)], \\
& =4^{\left|E_{1}(R)\right|} \times 6^{\left|E_{2}(R)\right|} \times 9^{\left|E_{3}(R)\right|}, \\
& =4^{(2 p+2 q+4)} \times 6^{(4 p+4 q-8)} \times 9^{(18 p q-11 p-11 q+4)}, \\
& M_{1}(G, x)=\sum_{u v \in E(G)} x^{[\operatorname{deg}(u)+\operatorname{deg}(v)]}, \\
& M_{1}(R, x)=\sum_{u v \in E_{1}(R)} x^{[\operatorname{deg}(u)+\operatorname{deg}(v)]} \\
& +\sum_{u v \in E_{2}(R)} x^{[\operatorname{deg}(u)+\operatorname{deg}(v)]}+\sum_{u v \in E_{3}(R)} x^{[\operatorname{deg}(u)+\operatorname{deg}(v)]}, \\
& =\sum_{u v \in E_{1}(R)} x^{4}+\sum_{u v \in E_{2}(R)} x^{5}+\sum_{u v \in E_{3}(R)} x^{6}, \\
& =\left|E_{1}(R)\right| x^{4}+\left|E_{2}(R)\right| x^{5}+\left|E_{3}(R)\right| x^{6}, \\
& =(2 p+2 q+4) x^{4}+(4 p+4 q-8) x^{5} \\
& +(18 p q-11 p-11 q+4) x^{6}, \\
& M_{2}(G, x)=\sum_{u v \in E(G)} x^{[\operatorname{deg}(u) \times \operatorname{deg}(v)]} \text {, }
\end{aligned}
$$




$$
\begin{aligned}
M_{2}(R, x) & =\sum_{u v \in E_{1}(R)} x^{[\operatorname{deg}(u) \times \operatorname{deg}(v)]} \\
& +\sum_{u v \in E_{2}(R)} x^{[\operatorname{deg}(u) \times \operatorname{deg}(v)]}+\sum_{u v \in E_{3}(R)} x^{[\operatorname{deg}(u) \times \operatorname{deg}(v)]} \\
& =\sum_{u v \in E_{1}(R)} x^{4}+\sum_{u v \in E_{2}(R)} x^{6}+\sum_{u v \in E_{3}(R)} x^{9} \\
& =\left|E_{1}(R)\right| x^{4}+\left|E_{2}(R)\right| x^{6}++\left|E_{3}(R)\right| x^{9} \\
& =(2 p+2 q+4) x^{4}+(4 p+4 q-8) x^{6} \\
& +(18 p q-11 p-11 q+4) x^{9}
\end{aligned}
$$

Theorem 3. Let $H$ be the line graph of the subdivision graph of $T U C_{4} C_{8}[p, q]$ nanotube. Then

$$
\begin{aligned}
M_{1}(H) & =108 p q-38 p \\
M_{2}(H) & =162 p q-67 p \\
H M(H) & =648 p q-264 p \\
P M_{1}(H) & =4^{2 p} \times 5^{4 p} \times 6^{(18 p q-11 p)}, \\
P M_{2}(H) & =4^{2 p} \times 6^{4 p} \times 9^{(18 p q-11 p)}, \\
M_{1}(H, x) & =2 p x^{4}+4 p x^{5}+(18 p q-11 p) x^{6}, \\
M_{2}(H, x) & =2 p x^{4}+4 p x^{6}+(18 p q-11 p) x^{9} .
\end{aligned}
$$

Proof. The subdivision graph of $T U C_{4} C_{8}[p, q]$ nanotube and the graph $H$ are shown in Fig. 4 (a) and (b) respectively. The graph $H$ contains $12 p q-2 p$ vertices of which $4 p$ vertices are of degree 2 and others are of degree 3 . Now using Lemma 1 it is easy to compute that the total number of edges of $H$ is $18 p q-5 p$. To prove the above statement the edge set $E(H)$ divides into three edge partitions based on degrees of end vertices,

$$
\begin{aligned}
& E_{1}(H)=\{u v \in E(H) \mid \operatorname{deg}(u)=2, \operatorname{deg}(v)=2\}, \\
& E_{2}(H)=\{u v \in E(H) \mid \operatorname{deg}(u)=2, \operatorname{deg}(v)=3\},
\end{aligned}
$$




$$
E_{3}(H)=\{u v \in E(H) \mid \operatorname{deg}(u)=3, \operatorname{deg}(v)=3\} .
$$

Among these three partitions of edge set correspond to their degree sum of neighbors of end vertices the number of edges in $E_{1}(H)$ are $2 p$, in $E_{2}(H G)$ are $4 p$ and in $E_{3}(H)$ are $18 p q-11 p$. Now using equations [(1)-(7)], we have

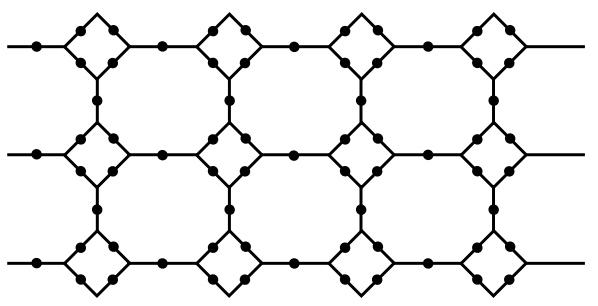

(a)

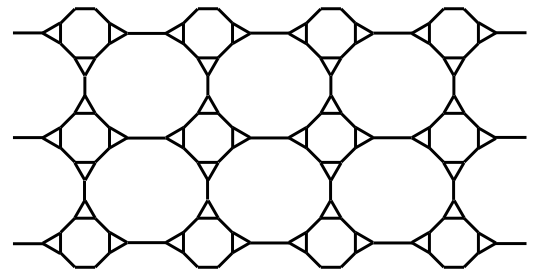

(b)

Figure 4: (a) Subdivision of $T U C_{4} C_{8}[4,3]$ nanotube; (b) Line graph of subdivision of $T U C_{4} C_{8}[4,3]$ nanotube.

$$
\begin{aligned}
M_{1}(G) & =\sum_{u v \in E(G)}[\operatorname{deg}(u)+\operatorname{deg}(v)], \\
M_{1}(H) & =\sum_{u v \in E_{1}(H)}[\operatorname{deg}(u)+\operatorname{deg}(v)] \\
& +\sum_{u v \in E_{2}(H)}[\operatorname{deg}(u)+\operatorname{deg}(v)]+\sum_{u v \in E_{3}(H)}[\operatorname{deg}(u)+\operatorname{deg}(v)], \\
& =4\left|E_{1}(H)\right|+5\left|E_{2}(H)\right|+6\left|E_{3}(H)\right|, \\
& =4(2 p)+5(4 p)+6(18 p q-11 p)=108 p q-38 p, \\
M_{2}(G) & =\sum_{u v \in E(G)}[\operatorname{deg}(u) \times \operatorname{deg}(v)],
\end{aligned}
$$

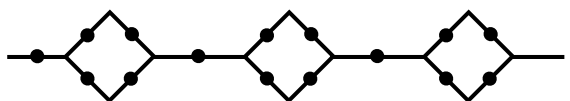

(a)

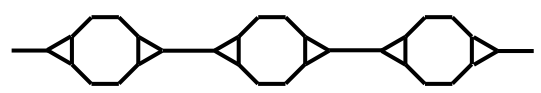

(b)

Figure 5: (a) Subdivision of $T U C_{4} C_{8}[3,1]$ nanotube; (b) Line graph of subdivision of $\mathrm{TUC}_{4} \mathrm{C}_{8}[3,1]$ nanotube. 


$$
\begin{aligned}
& M_{2}(H)=\sum_{u v \in E_{1}(H)}[\operatorname{deg}(u) \times \operatorname{deg}(v)] \\
& +\sum_{u v \in E_{2}(H)}[\operatorname{deg}(u) \times \operatorname{deg}(v)]+\sum_{u v \in E_{3}(H)}[\operatorname{deg}(u) \times \operatorname{deg}(v)], \\
& =4\left|E_{1}(H)\right|+6\left|E_{2}(H)\right|+9\left|E_{3}(H)\right|, \\
& =4(2 p)+6(4 p)+9(18 p q-11 p)=162 p q-67 p \text {, } \\
& H M(G)=\sum_{u v \in E(G)}[\operatorname{deg}(u)+\operatorname{deg}(v)]^{2}, \\
& H M(H)=\sum_{u v \in E_{1}(H)}[\operatorname{deg}(u)+\operatorname{deg}(v)]^{2} \\
& +\sum_{u v \in E_{2}(H)}[\operatorname{deg}(u)+\operatorname{deg}(v)]^{2}+\sum_{u v \in E_{3}(H)}[\operatorname{deg}(u)+\operatorname{deg}(v)]^{2}, \\
& =16\left|E_{1}(H)\right|+25\left|E_{2}(H)\right|+36\left|E_{3}(H)\right| \text {, } \\
& =16(2 p)+25(4 p)+36(18 p q-11 p)=648 p q-264 p \text {, } \\
& P M_{1}(G)=\prod_{u v \in E(G)}[\operatorname{deg}(u)+\operatorname{deg}(v)], \\
& P M_{1}(H)=\prod_{u v \in E_{1}(H)}[\operatorname{deg}(u)+\operatorname{deg}(v)] \\
& \times \prod_{u v \in E_{2}(H)}[\operatorname{deg}(u)+\operatorname{deg}(v)] \times \prod_{u v \in E_{3}(H)}[\operatorname{deg}(u)+\operatorname{deg}(v)], \\
& =4^{\left|E_{1}(H)\right|} \times 5^{\left|E_{2}(H)\right|} \times 6^{\left|E_{3}(H)\right|}, \\
& =4^{2 p} \times 5^{4 p} \times 6^{(18 p q-11 p)}, \\
& P M_{2}(G)=\prod_{u v \in E(G)}[\operatorname{deg}(u) \times \operatorname{deg}(v)] \\
& P M_{2}(H)=\prod_{u v \in E_{1}(H)}[\operatorname{deg}(u) \times \operatorname{deg}(v)] \\
& \times \prod_{u v \in E_{2}(H)}[\operatorname{deg}(u) \times \operatorname{deg}(v)] \times \prod_{u v \in E_{3}(H)}[\operatorname{deg}(u) \times \operatorname{deg}(v)], \\
& =4^{\left|E_{1}(H)\right|} \times 6^{\left|E_{2}(H)\right|} \times 9^{\left|E_{3}(H)\right|},
\end{aligned}
$$




$$
\begin{aligned}
= & 4^{2 p} \times 6^{4 p} \times 9^{(18 p q-11 p)}, \\
M_{1}(G, x) & =\sum_{u v \in E(G)} x^{[\operatorname{deg}(u)+\operatorname{deg}(v)]}, \\
M_{1}(H, x) & =\sum_{u v \in E_{1}(H)} x^{[\operatorname{deg}(u)+\operatorname{deg}(v)]} \\
& +\sum_{u v \in E_{2}(H)} x^{[\operatorname{deg}(u)+\operatorname{deg}(v)]}+\sum_{u v \in E_{3}(H)} x^{[\operatorname{deg}(u)+\operatorname{deg}(v)]}, \\
& =\sum_{u v \in E_{1}(H)} x^{4}+\sum_{u v \in E_{2}(H)} x^{5}+\sum_{u v \in E_{3}(H)} x^{6}, \\
& =E_{1}(H)\left|x^{4}+\right| E_{2}(H)\left|x^{5}++\right| E_{3}(H) \mid x^{6}, \\
M_{2}(G, x) & =\sum_{u v \in E(G)} x^{[\operatorname{deg}(u) \times \operatorname{deg}(v)]}, \\
M_{2}(H, x) & =\sum_{u v \in E_{1}(H)} x^{[\operatorname{deg}(u) \times \operatorname{deg}(v)]} \\
& +\sum_{u v \in E_{2}(H)} x^{[\operatorname{deg}(u) \times \operatorname{deg}(v)]}+\sum_{u v \in E_{3}(H)} x^{[\operatorname{deg}(u) \times \operatorname{deg}(v)]}, \\
& =\sum_{u v \in E_{1}(H)} x^{4}+\sum_{u v \in E_{2}(H)} x^{6}+\sum_{u v \in E_{3}(H)} x^{9}, \\
& =E_{1}(H)\left|x^{4}+\right| E_{2}(H)\left|x^{6}++\right| E_{3}(H) \mid x^{9}, \\
& 2 p x^{4}+4 p x^{6}+(18 p q-11 p) x^{9} .
\end{aligned}
$$

Theorem 4. Let $K$ be the line graph of the subdivision graph of $T U C_{4} C_{8}[p, q]$ nanotorus. Then

$$
\begin{aligned}
M_{1}(K) & =108 p q, \\
M_{2}(K) & =162 p q, \\
H M(K) & =648 p q, \\
P M_{1}(K) & =6^{18 p q}, \\
P M_{2}(K) & =9^{18 p q}, \\
M_{1}(K, x) & =18 p q x^{6}, \\
M_{2}(K, x) & =18 p q x^{9} .
\end{aligned}
$$


Proof. The subdivision graph of $T U C_{4} C_{8}[p, q]$ nanotorus and the graph $K$ are shown in Fig. 6 (a) and (b) respectively. In $K$, there are total $12 p q$ vertices and all of them are of degree 3 . Now Lemma 1 implies that the total number of edges of $K$ is $18 p q$. Therefore we get the trivial edge partition, based on the degrees of the vertices i.e $E_{1}(K)=\{u v \in E(K) \mid \operatorname{deg}(u)=3, \operatorname{deg}(v)=3\}$ with $\left|E_{1}(K)\right|=18 p q$. Now using equations [(1)-(7)], we have

$$
\begin{aligned}
M_{1}(G) & =\sum_{u v \in E(G)}[\operatorname{deg}(u)+\operatorname{deg}(v)], \\
M_{1}(K) & =\sum_{u v \in E_{1}(K)}[\operatorname{deg}(u)+\operatorname{deg}(v)]=6\left|E_{1}(K)\right|, \\
& =6(18 p q)=108 p q .
\end{aligned}
$$

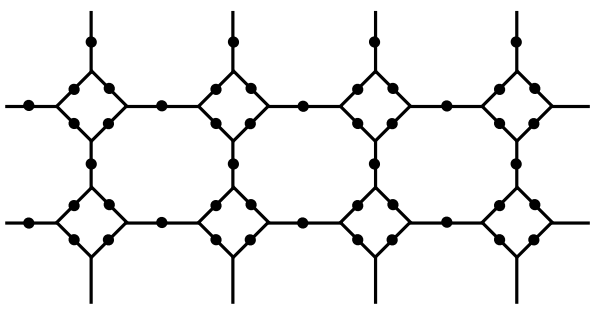

(a)

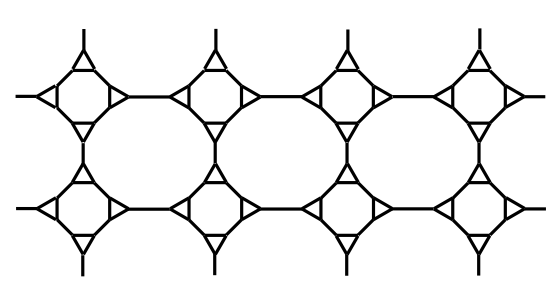

(b)

Figure 6: (a) Subdivision of $T U C_{4} C_{8}[4,2]$ nanotorus; (b) Line graph of Subdivision of $\mathrm{TUC}_{4} C_{8}[4,2]$ nanotorus.

$$
\begin{aligned}
M_{2}(G) & =\sum_{u v \in E(G)}[\operatorname{deg}(u) \times \operatorname{deg}(v)], \\
M_{2}(K) & =\sum_{u v \in E_{1}(K)}[\operatorname{deg}(u) \times \operatorname{deg}(v)], \\
& =9\left|E_{1}(K)\right|=9(18 p q)=162 p q, \\
H M(G) & =\sum_{u v \in E(G)}[\operatorname{deg}(u)+\operatorname{deg}(v)]^{2}, \\
H M(K) & =\sum_{u v \in E_{1}(K)}[\operatorname{deg}(u)+\operatorname{deg}(v)]^{2},
\end{aligned}
$$




$$
\begin{aligned}
& =6^{2} \mid E_{1}(K)=36(18 p q)=648 p q, \\
& P M_{1}(G)=\prod_{u v \in E(G)}[\operatorname{deg}(u)+\operatorname{deg}(v)], \\
& P M_{1}(K)=\prod_{u v \in E_{1}(K)}[\operatorname{deg}(u)+\operatorname{deg}(v)]=6^{\left|E_{1}(K)\right|}=6^{18 p q}, \\
& P M_{2}(G)=\prod_{u v \in E(G)}[\operatorname{deg}(u) \times \operatorname{deg}(v)], \\
& P M_{2}(K)=\prod_{u v \in E_{1}(K)}[\operatorname{deg}(u) \times \operatorname{deg}(v)]=9^{\left|E_{1}(K)\right|}=9^{18 p q}, \\
& M_{1}(G, x)=\sum_{u v \in E(G)} x^{[\operatorname{deg}(u)+\operatorname{deg}(v)]}, \\
& M_{1}(K, x)=\sum_{u v \in E_{1}(K)} x^{[\operatorname{deg}(u)+\operatorname{deg}(v)]}=\sum_{u v \in E_{1}(K)} x^{6}=18 p q x^{6}, \\
& M_{2}(G, x)=\sum_{u v \in E(G)} x^{[\operatorname{deg}(u) \times \operatorname{deg}(v)]}, \\
& M_{2}(K, x)=\sum_{u v \in E_{1}(K)} x^{[\operatorname{deg}(u) \times \operatorname{deg}(v)]}=\sum_{u v \in E_{1}(K)} x^{9}=18 p q x^{9} .
\end{aligned}
$$

\section{Conclusions}

In this paper, we have computed hyper Zagreb index, first multiple Zagreb index, second multiple Zagreb index and Zagreb polynomials of the line graph of $2 D$-lattice, nanotube and nanotorus of $T U C_{4} C_{8}[p, q]$ by using the concept of subdivision. In future we are interested to find some other restructures and compute their topological indices of their line graphs. 


\section{Acknowledgement}

This work was supported by the Teaching Groups in Anhui Province (2016jytd080); the Natural Science Foundation of the Education Department of Anhui Province (KJ2019A1303); the Key Program of the Excellent Young Talents Support of Higher Education in Anhui Province (gxyq2018116); the Natural Science Foundation of Bozhou University (BYZ2018B03).

\section{References}

[1] M. Bača, J. Horváthová, M. Mokrišová, A. Suhányiová, On topological indices of fullerenes, Appl. Math. Comput., 251 (2015), 154-161.

[2] M. Bača, J. Horváthová, M. Mokrišová, A. Semanicová-Fenovcíková, A. Suhányiová, On topological indices of carbon nanotube network, Canad. J. Chem., 93 (2015), 1-4.

[3] K.C. Das, On geometricarithmetic index of graphs, MATCH Commun. Math. Comput. Chem., 64 (2010), 619-630.

[4] M. Eliasi, A. Iranmanesh, I. Gutman, Multiplicative version of first zagreb index, MATCH Commun. Math. Comput. Chem., 68 (2012), 217-230.

[5] B. Furtula, I. Gutman, M. Dehmer, On structure-sensitivity of degreebased topological indices, Appl. Math. Comput., 219 (2013), 8973-8978.

[6] M.R. Farahani, The hyper zegreb index of $T U S C_{4} C_{8}(S)$ nanotubes, Int. J. Engin. Tech. Rese, 3, No 1 (2015), 1-6.

[7] W. Gao, M.K. Siddiqui, M. Imran, M.K. Jamil, M.R. Farahani, Forgotten topological index of chemical structure in drugs, Saudi Pharmaceutical J., 24 (2016), 258-267.

[8] W. Gao, M.K. Siddiqui, Molecular descriptors of nanotube, Oxide, Silicate, and triangulene networks, J. of Chemistry, 2017, Article ID 6540754, 1-10.

[9] W. Gharibi, A. Ahmad, M.K. Siddiqui, On Zagreb indices, Zagreb polynomials of nanocone and nNanotubes, J. Comput. Theor. Nanosci., 13 (2016), 5086-5092.

[10] M. Ghorbani, N. Azimi, Note on multiple Zagreb indices, Iran. J. Math. Chem., 3, No 2 (2012), 137-143. 
[11] M. Ghorbani, Optoelectronics and Advanced Materials-Rapid Communications, 4 (2010), 261-268.

[12] I. Gutman, K.C. Das, Some properties of the second Zagreb index, MATCH Commun. Math. Comput. Chem., 50 (2004), 103-112.

[13] I. Gutman, O.E. Polansky, Mathematical Concepts in Organic Chemistry, Springer-Verlag, New York, 1986.

[14] I. Gutman, N. Trinajstic, Graph theory and molecular orbitals. Total felectron energy of alternant hydrocarbons, Chem. Phys. Lett., 17 (1972), $535-538$.

[15] S. Hayat, M. Imran, Computation of topological indices of certain networks, Appl. Math. Comput., 240 (2014), 213-228.

[16] S. Hayat, M. Imran, Computation of certain topological indices of nanotubes covered by $C_{5}$ and $C_{7}$, J. Comput. Theor. Nanosci., 12 (2015), $1-9$.

[17] M. Imran, S. Hayat, M.Y.H. Mailk, On topological indices of certain interconnection networks, Appl. Math. Comput., 244 (2014), 936-951.

[18] A. Mahmiani, A. Iranmanesh, EdgeSzeged Index of $H A C 5 C 7[r, p]$ nanotube, MATCH Commun. Math. Comput. Chem., 62 (2009), 397-417.

[19] M.F. Nadeem, S. Zafar, Z. Zahid, Certain topological indicies of the line graph of subdivsion graphs, Appl. Math. Comput., 271 (2015), 790-794.

[20] M.F. Nadeem, S. Zafar, Z. Zahid, Certain topological indicies of the line graph of subdivsion graphs, Appl. Math. Comput., 273 (2016), 125-130.

[21] J. Rada, R. Cruz, I. Gutman, Benzenoid systems with extremal vertexdegree-based topological indices, MATCH Commun. Math. Comput. Chem., 72 (2014), 125-136.

[22] J. Rada, R. Cruz, Vertex-degree-based topological indices over graphs, MATCH Commun. Math. Comput. Chem., 72 (2014), 603-616.

[23] P.S. Ranjini, V. Lokesha, I.N. Cangl, On the Zagreb indices of the line graphs of the subdivision graphs, Appl. Math. Comput., 218 (2011), 699702. 
[24] P.S. Ranjini, V. Lokesha, M.A. Rajan, On the Shultz index of the subdivision graphs, Adv. Stud. Contemp. Math., 21, No 3 (2011), 279-290.

[25] M.K. Siddiqui, M. Imran, A. Ali, On Zagreb indices, Zagreb polynomials of some nanostar dendrimers, Appl. Math. Comput., 280 (2016), 132-139.

[26] M.K. Siddiqui, W. Gharibi, On Zagreb indices, Zagreb polynomials of mesh derived networks, J. Comput. Theor. Nanosci., 13 (2016), 8683-8688.

[27] M.K. Siddiqui, M. Naeem, N. A. Rahman, M. Imran, Computing topological indices of certain networks, J. Optoelectronics and Advanced Materials, 18, No 9-10 (2016), 884-892.

[28] G.H. Shirdel, H. RezaPour and A.M. Sayadi, The hyper Zagreb index of graph operations, Iran. J. Math. Chem., 4, No 2 (2013), 213-220.

[29] G. Su, L. Xu, Topological indices of the line graph of subdivision graphs and their Schur-bounds, Appl. Math. Comput., 253 (2015), 395-401.

[30] H. Wiener, Structural determination of paraffin boiling points, J. Am. Chem. Soc., 69 (1947), 17-20. 
